\title{
Analisa pengaruh Beban Terhadap Stabilitas Statis Kapal Patroli 28 Meter Untuk Pengawasan Perairan di Kepulauan Riau
}

\author{
Hendra Saputra, Nidia Yuniarsih, dan Desrial Rianto \\ Program Studi Teknik Perencanaan dan Konstruksi Kapal, Jurusan Teknik Mesin, Politeknik Negeri \\ Batam \\ Jl. Ahmad Yani, Batam Centre, Batam 29461, Indonesia \\ E-mail: hendrasaputra@polibatam.ac.id
}

\begin{abstract}
Abstrak
Stabilitas adalah kemampuan sebuah kapal untuk kembali tegak semula setelah miring yang disebabkan pengaruh gaya dari aktivitas di kapal, baik yang datang dari luar maupun dari dalam kapal. Peraturan keselamatan internasional, yang telah ditetapkan pada bulan November 1993. Komisi keselamatan maritime dari IMO (International Maritime Organization) sedang mengembangkan persyaratan untuk diterima oleh para pihak menandatangani Konvensi Internasional untuk keselamatan jiwa di laut SOLAS 1974 (Safety Of Life At Sea 1974), dimana dipenuhi ISM Code menjadi keharusan[1]. Kapal patroli 28 meter ini merupakan kapal cepat yang digunakan untuk melakukan pengawasan dan keamanan diwilayah perairan Kepulauan Riau, sehingga faktor teknis seperti stabilitas dan titik berat kapal menjadi penting untuk diperhatikan agar dapat meminimalisir terjadinya kecelakaan dilaut. Penelitian ini bertujuan untuk mengetahui pengaruh beban terhadap stabilitas statis pada kapal patroli 28 meter. Metode yang dilakukan adalah melakukan proses inclining test. Dan hasil yang didapat adalah tinggi metacenter dan nilai GZ kapal patroli 28 meter. Dari hasil analisa dan pembahasan didapatkan bahwa tinggi metacenter sudah memenuhi ketentuan yang ditetapkan oleh BKI dan IMO, untuk nilai GZ kapal ini telah memenuhi standar yang ditetapkan oleh IMO.
\end{abstract}

Kata Kunci: Stabilitas Statis, Kapal Patroli 28 Meter, Peraturan Keselamatan Internasional, Inclining Test, IMO, BKI

\begin{abstract}
Stability is the ability of a vessel to return to a previous position. Positive stability would then be to return to upright and negative stability would be to overturn. The Maritime Safety Commission of the IMO (International Maritime Organization) develops a requirements for acceptance by parties of the International SOLAS Convention for the Safety of Life At Sea 1974 (SOLAS 1974), where ISM Code is compliant [1]. This paper aims to determine the effect of load on ship static stability on 28 meter patrol boat. The 28 meter patrol boat is a fast surveillance vessels for Kepulauan Riau region. Technically, the ship stabily is one of the important factor to take note in order to minimize the occurrence of accidents. Methodology used in this paper by applying inclining test to the ship. Height of metacenter and righting arms (GZ) are obtained from the test and shows that the both metacenter and GZ was passed the requirement of Biro Klasifikasi Indonesia (BKI) and IMO regulation.
\end{abstract}

\section{Keywords : Static Stability, Patrol Boat 28 Meter, International Safety Regulations, Inclining Test, IMO, BKI}

\section{Pendahuluan}

Aplikasi ISM (International Safety Management) code diberlakukan untuk semua kapal, tetapi dalam pelaksanaannya masih banyak terjadi kecelakaan pelayaran, dan sesuai informasi dari Komite Nasional Keselamatan Transsportasi ( KNKT ), edisi database KNKT 30 November 2016 adalah sebagai berikut [2] :

a. Tahun 2014 terdapat 7 kasus yang terdiri dari 2 kasus kapal tenggelam, 3 kasus kapal terbakar, 2 kasus kapal tubrukan, selain itu sebanyak 22 orang meninggal, dan 4 orang luka-luka. b. Tahun 2015 meningkat sebanyak 11 kasus, yang terdiri dari 3 kasus kapal tenggelam, 4 kasus kapal terbakar, 3 kasus kapal tubrukan, 1 kasus kapal kandas, selain itu korban jiwa pun meningkat yang terdiri dari, 85 orang meninggal, dan 2 orang luka-luka.

c. Tahun 2016 terus meningkat menjadi 15 kasus, yang terdiri dari 4 kasus kapal tenggelam, 4 kasus kapal terbakar, 3 kasus kapal tubrukan, 2 kasus kapal kandas, 2 kasus kapal lainnya, selain itu sebanyak 51 orang meninggal, dan 18 orang luka-luka. 


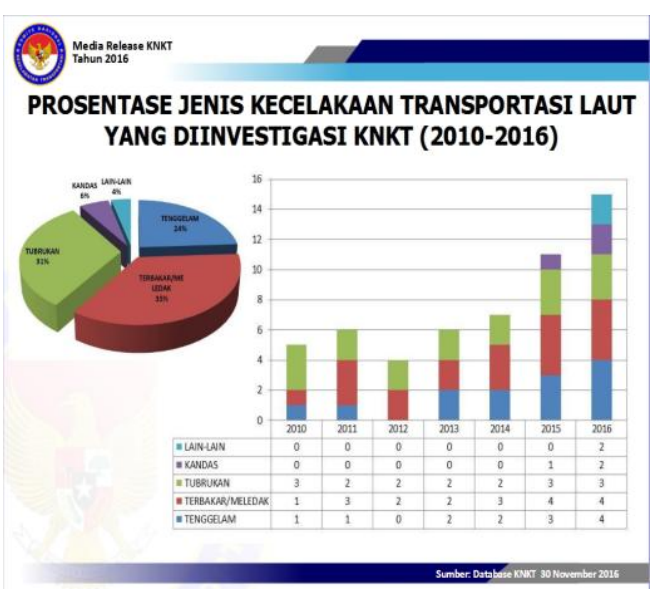

Figure 1: Persentase Kecelakaan Laut [2]

Penyebab utama kecelakaan karena kelebihan muatan yang diangkut melebihi DWT kapal, dan tidak memenuhi aturan layak laut, seperti muatan tidak diikat (di-lashing) yang dapat mempengaruhi stabilitas kapal, dengan alasan jarak pelabuhan tujuan dekat, hanya memerlukan waktu kurang dari satu hari, contoh kecelakaan kapal dari Johor - Batam akibat kelebihan muatan [2].

keselamatan suatu kapal salah satunya ditentukan oleh stabilitas pada kapal [3], Stabilitas adalah kemapuan kapal untuk kembali ke posisi semula setelah mengalami gaya dari luar maupun dari dalam kapal yang menyebabkan kapal itu miring.Bahwa pada suatu benda yang mengapung diam di pemukaan air terdapat dua gaya yang sama besar dan bekerja berlawanan arah pada sumbu vertikal kapal, yaitu gaya berat (center of gravity) dan gaya apung (center of bouyancy) [4].

Ada tiga titik yang memiliki peranan penting dalam stabilitas kapal yaitu:

- Titik berat (centre of gravity)

Resultan gaya berat seluruh kapal termasuk semua isi yang berada didalam kapal dan menekan kebawah.

- Titik apung (centre of bouyancy)

Titik berat geometris dikapal yang terbenam di air yang menekan ke atas, titik apung bukanlah merupakan titik yang tetap melainkankan berubah-ubah tergantung dari sarat kapal.

- Titik Metacenter

Sebuah titik semu dimana titik $G$ tidak boleh melewati batas diatasnya agar kapal tetap memiliki stabilitas yang positif. Meta artinya berubah-ubah,jadi titik metacenter dapat berubah-ubah tergantung dari kemiringan kapal [5] [6].
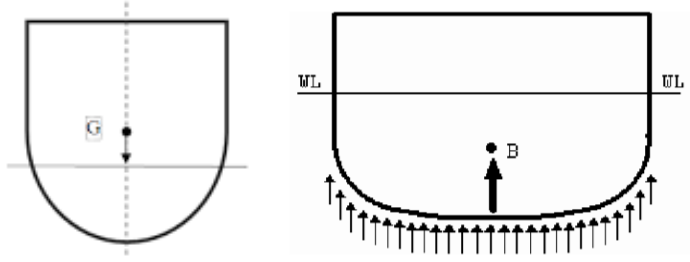

(a)

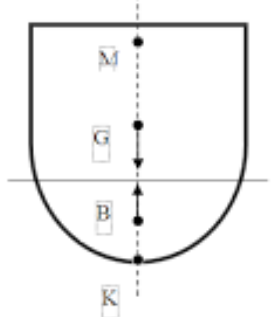

(c)

Figure 2. Titik stabilitas kapal (a) Titik berat (centre of gravity) (b) Titik apung (centre of bouyancy) (c) Titik Metacenter

Kapal patroli adalah kapal cepat yang digunakan untuk pengawasan dan keamanan diwilayah tertentu, sehingga stabilitas kapal ini menjadi aspek penting untuk mendapatkan perhatian agar meminimalisir terjadinya kecelakaan kapal [7].

Oleh karena itu penelitian ini bertujuan untuk mengetahui pengaruh beban terhadap stabilitas statis kapal patroli 28 meter, untuk mendapatkan gaya-gaya utama yang mempengaruhi stabilitas seperti tinggi metacenter dan nilai GZ kapal tersebut. Stabilitas statis merupakan stabilitas saat kapal dalam keadaan diam.

Penelitian tentang stabilitas ini juga ditujukan untuk mengetahui kondisi kapal dengan berbagai kondisi muatan. Kondisi muatan yang dimaksud seperti jumlah muatan maupun posisi muatan diatas kapal. Dengan begitu $\mathrm{ABK}$ dapat memperkirakan berapa beban maksimum dan penempatan muatan yang optimal [8].

Dalam penelitian ini metode yang dilakukan adalah inclining test atau yang sering disebut uji kemiringan kapal merupakan uji stabilitas dalam menyelesaikan pembutan kapal baru, sehingga didapatkan hasil penelitian tersebut [5]

\section{Metodologi Penelitian}

\section{1) Ship Particular}

Untuk memperlancar penelitian ini dibutuhkan data-data utama kapal sebagai berikut :

TABEL 1

SHIP PARTICULAR

\begin{tabular}{|l|l|}
\hline Ship type & Patroli \\
\hline LOA & $28 \mathrm{~m}$ \\
\hline LPP & $25.58 \mathrm{~m}$ \\
\hline Breadth & $5.85 \mathrm{~m}$ \\
\hline Depth & $3.1 \mathrm{~m}$ \\
\hline Draft & $1.0 \mathrm{~m}$ \\
\hline Lightship weight & 40.23 Ton \\
\hline
\end{tabular}




\section{2) Metode Pengujian}

Metode yang dilakukan dalam penelitian ini adalah metode experiment yaitu inclining test, yang mengacu pada rules BKI. Berikut prosedur melakukan inclining test [9] :

a. Persiapan Pengujian.

- Informasi yang diperlukan dalam proses pengujian seperti, tanggal dan waktu pelaksanaan, gambar rencana umum, kapasitas tangki, dan lokasi tanda sarat.

- Kapal harus sudah mendekati penyelesaian akhir, sebelum pengujian kemiringan dilakukan daftar semua barang yang dinaikan kekapal, diturunkan, atau dipindahkan harus dicatat dengan cermat.

- Barang yang mudah bergeser harus terikat ditempatnya.

- Secara umum hanya personil yang bertugas dalam pengujian kemiringan yang diizinkan berada diatas kapal.

- Diusahakan agar semua tangki berada dalam kondisi penuh atau kosong.

- Tali tambat harus bebas tegangan selama pembacaan hasil uji dan tidak boleh adanya momen yang ditimbulkan akibat tali tambat.

- Untuk pengujian kemiringan sebaiknya menggunakan beban uji benda padat. Beban uji harus cukup untuk memiringkan kapal paling sedikit $1^{\circ}$ dan paling besar $4^{\circ}$ pada setiap sisi kapal terhitung dari posisi awal.

- Kemiringan kapal yang diizinkan pada posisi awal tidak melebihi $0,50^{\circ}$.

b. Pengujian Kemiringan dan Pencatatan.

- Personil yang bertanggung jawab dalam pengujian harus orang ahli dibidangnya dan pengambilan data harus sesuai persetujuan surveyor BKI.

- Sarat air harus diukur menjelang dan setelah pengujian.

- Urutan pemindahan uji dapat dilihat sesuai table 2.2.

- Posisi beban uji harus diberi tanda diatas geladak untuk menjamin pemindahan dilakukan dengan konsisten.

Dalam pemindahan beban uji memiliki prosedur dan tahap-tahap pemindahan beban, Berikut gambar prosedur pemindahan beban uji pada proses inclining test :
TABLE 2

PEMINDAHAN BEBAN [9]

\begin{tabular}{|c|c|c|}
\hline & \multicolumn{2}{|c|}{$\begin{array}{c}\text { Jumlah beban atau } \\
\text { kelompok beban }\end{array}$} \\
\cline { 2 - 3 } $\begin{array}{c}\text { Urutan } \\
\text { Pemindahan } \\
\text { Beban }\end{array}$ & \multicolumn{2}{|c|}{ Empat } \\
\cline { 2 - 3 } & Kiri & Kanan \\
\hline No. 0 & 2,4 & 1,3 \\
\hline No. 1 & 4 & $1, \underline{2}, 3$ \\
\hline No. 2 & $\underline{1}$ & $1,2,3, \underline{4}$ \\
\hline No. 3 & $1, \underline{3}$ & 2,4 \\
\hline No. 4 & $1, \underline{2}, 3$ & 4 \\
\hline No. 5 & $1,2,3, \underline{4}$ & \\
\hline No. 6 & $2,3,4$ & $\underline{1}$ \\
\hline No. 7 & 2,4 & $1, \underline{3}$ \\
\hline No. 8 & &
\end{tabular}

Kiri dan kanan menunjukan posisi sebelah kiri dan kanan kapal, nomor yang diberi garis bawah menyatakan beban yang terakhir dipindahkan

Initial Position<smiles>BrC1CCC1</smiles>

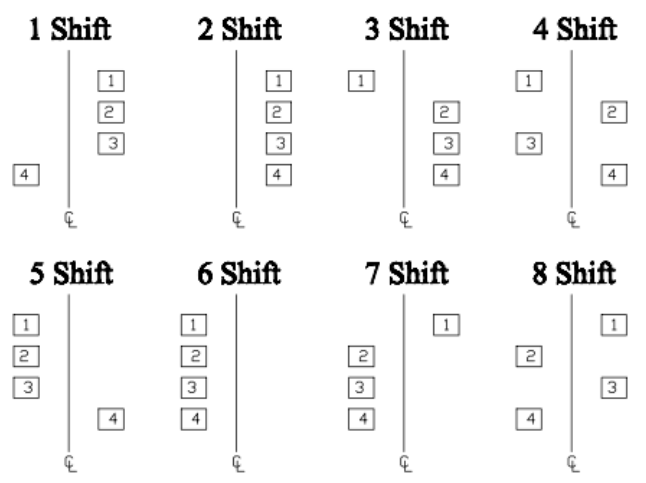

Figure 3: Prosedur Pemindahan Beban

Menurut rules BKI untuk peletakan beban beban harus diberi tanda untuk menjamin pemindahan dilakukan dengan konsisten, Berikut skema peletakan beban dan pendulum diatas kapal :

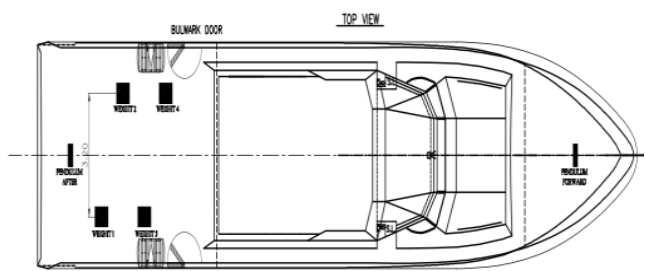




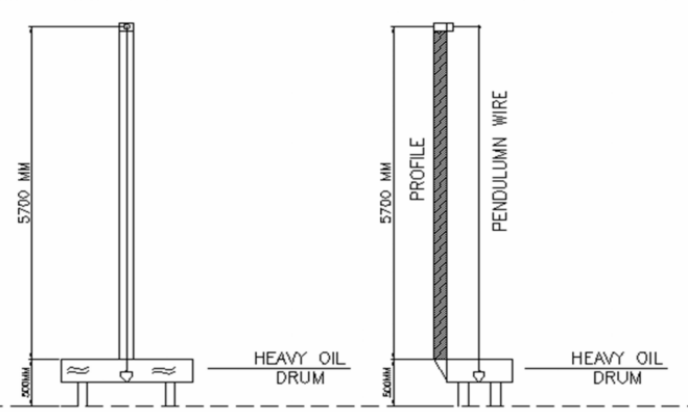

Figure 4: Skema Letak Beban dan Pendulum

\section{1) Perhitungan Tinggi Metacenter $\left(\mathbf{G M}_{0}\right)$.}
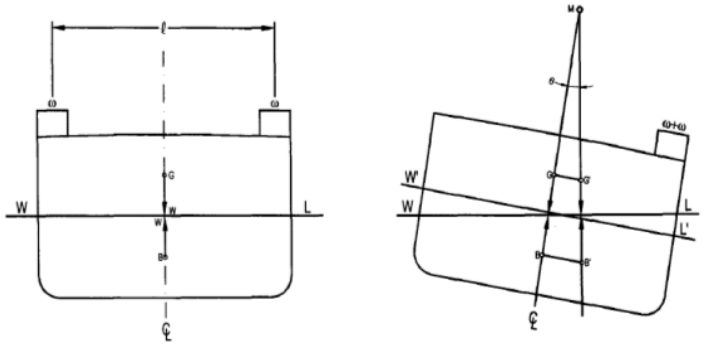

Figure 5: Tinggi Metacenter

Jarak perpindahan titik pusat gravitasi GG' didapatkan akibat adanya pergeseran pada beban uji, dan akan diperoleh rumus sebagai berikut :

$\mathbf{G G}^{\prime}=\underline{\mathbf{w} \times \mathbf{l}}$

\author{
W \\ $\mathrm{GG}^{\prime}=\mathrm{GM}_{0} \times \tan \theta$
}

Dari rumus 1 dan 2 dapat diperoleh nilai

$$
\mathbf{G M}_{0}=\frac{w \times 1}{W \times \tan \theta}
$$

Keterangan :

$G G^{\prime} \quad$ : Jarak perpindahan titik pusat gravitasi (m)

$G M_{0} \quad$ Tinggi metacenter (m)

$W \quad$ Displacement kapal (ton)

$l \quad$ Jarak perpindahan beban uji (m)

$\Theta \quad$ Sudut kemiringan kapal $\left(^{0}\right)$

w Berat beban uji (ton)

\section{Analisa Data dan Pembahasan}

Kapal Patroli 28 meter milik Direktorat Kesatuan Penjagaan laut dan Pantai terdaftar di Class Biro Klasifikasi Indonesia, Oleh karena itu semua aturan dan ketentuan dalam pembangunan kapal ini mengacu kepada rules BKI, termasuk pada saat proses uji kemiringan kapal.

\section{1) Laporan Pengujian Kemiringan Kapal}

Bedasarkan ketentuan yang telah ada, sebelum dilakukan pengujian kemiringan kapal ada beberapa informasi yang dibutuhkan guna memperlancar pada saat pengujian berlangsung, Lihat tabel 3.1 Laporan Pengujian Kemiringan Kapal 1.

TABEL 3

\begin{tabular}{|c|c|c|c|c|c|}
\hline \multicolumn{6}{|c|}{ LAPORAN PENGUJIAN KEMIRINGAN KAPAL } \\
\hline \multicolumn{6}{|c|}{ REPORT ON INCLINING TEST } \\
\hline Type Kapal & Patroli & Pemilik Kapal & \multicolumn{3}{|c|}{ Direktorat Kesatuan Penjagaan Laut Dan Pantai } \\
\hline Material Kapal & Alumunium & Tempat Peluncuran & \multicolumn{3}{|c|}{ Batam } \\
\hline Pelabuhan Pendaftaran & Batam & Jumlah \& Tipe Mesin Induk & \multicolumn{3}{|c|}{$2 \times 1300 \mathrm{HP}$} \\
\hline Tempat Pelaksanaan & \multicolumn{5}{|c|}{ PT. Batam Expresindo Shipyard } \\
\hline \multirow{3}{*}{$\begin{array}{l}\text { Jumlah personil yang } \\
\text { diizinkan diatas kapal }\end{array}$} & $\mathrm{ABK}$ & 0 & \multirow{3}{*}{ Principal Dimensions } & Panjang (LOA) & $28 \mathrm{~m}$ \\
\hline & Lain-lain & 7 & & Lebar & $5,85 \mathrm{~m}$ \\
\hline & Jumlah & 7 & & Tinggi & $3,10 \mathrm{~m}$ \\
\hline
\end{tabular}

LAPORAN PENGUJIAN KEMIRINGAN KAPAL 1

Setelah semua data dan informasi yang dibutuhkan telah tersedia maka proses pengujian selanjutnya dapat dilaksankan. Dari hasil pengujian kemiringan kapal yag telah dilakukan dengan berat masing-masing beban adalah 1,105 ton maka total berat beban yaitu 4,42 ton. Dan jarak pergeseran beban sejauh 4,2 m. Menurut rules yang telah ditentukan oleh Biro Klasifikasi indonesia bahwa untuk letak dan pemindahan beban diberi tanda agar pengukuran dan hasil yang didapatkan konsisten, dan untuk posisi sarat air harus dicatat dengan cermat agar tidak menimbulkan kekeliruan pada saat pembacaan hasil uji.

Laporan pengujian kemiringan dengan 3 kondisi yaitu kondisi kapal penuh termasuk tahanan, kondisi kapal penuh tanpa tahanan, dan kondsi kapal kosong. 
TABEL 4

LAPORAN PENGUJIAN KEMIRINGAN KAPAL (KONDISI KAPAL PENUH TERMASUK TAHANAN)

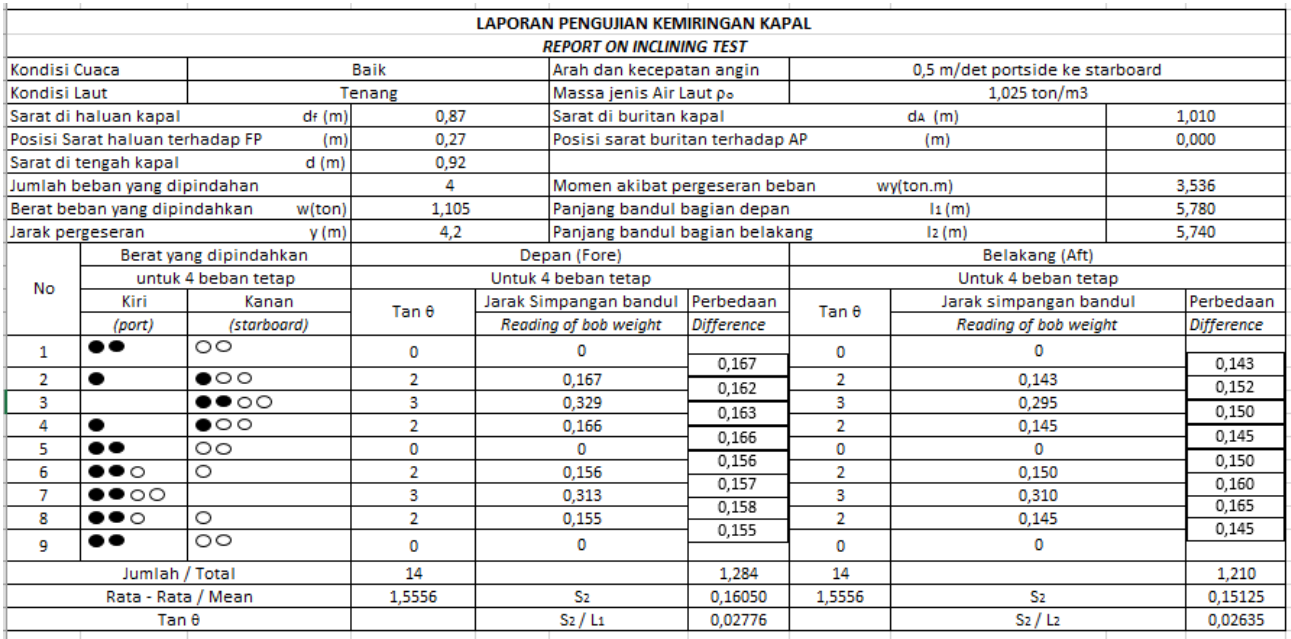

TABEL 5

LAPORAN PENGUJIAN KEMIRINGAN KAPAL (KONDISI KAPAL PENUH TANPA TAHANAN)

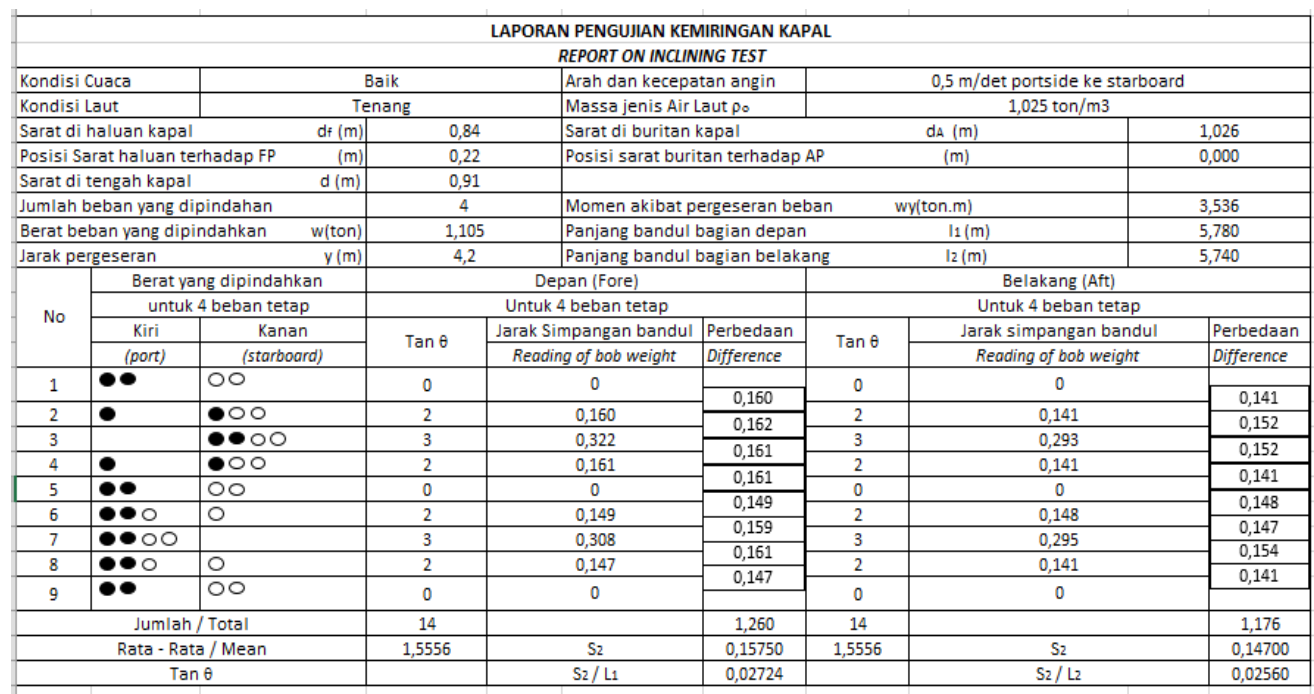

TABEL 6

LAPORAN PENGUJIAN KEMIRINGAN KAPAL (KONDISI KAPAL KOSONG)

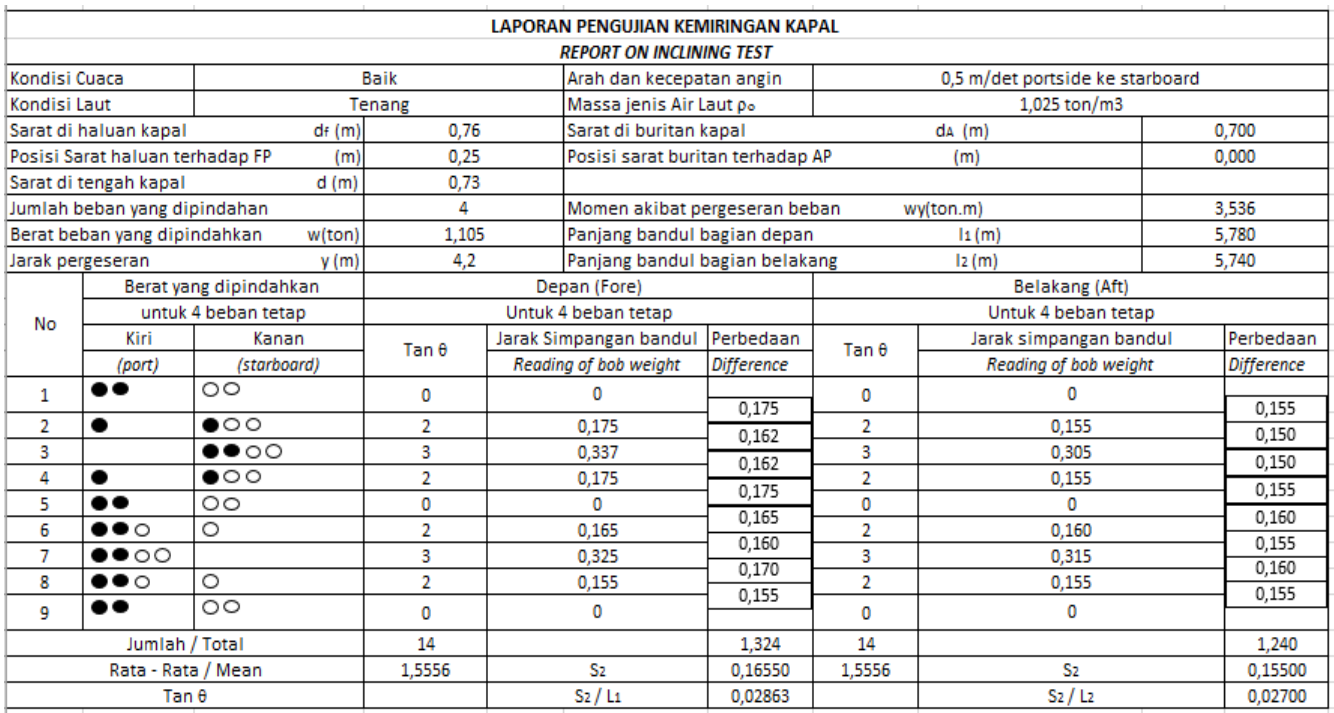


Sesuai dengan rules yang telah ditetapkan oleh BKI bahwa semua tangki harus berada dalam kondisi kosong atau penuh, jumlah tangki yang berisi diusahakan sedikit mungkin. Volume dan massa jenis cairan dalam tangki harus diketahui.

Pada proses pengujian Kapal Patroli 28 m ini semua tangki berada dalam keadaan kosong dan penuh, Pada saat pengujian dengan isi tangki kosong, ada satu tangki yang berisi yaitu tangki harian (Daily Tank) dengan isi tangki 0,632 ton, dan sudah mendapat persetujuan dari Surveyor BKI bahwa tangki tersebut tidak dalam kondisi kosong dikarenkan rules telah mengatur tngki harian harus terisi sesuai kondisi kerjanya, berikut laporan mengenai tangki:

TABEL 7

LAPORAN PENGUJIAN KEMIRINGAN KAPAL (KAPASITAS TANGKI)

\begin{tabular}{|c|c|c|c|c|c|c|c|}
\hline \multicolumn{8}{|c|}{ LAPORAN PENGUJIAN KEMIRINGAN KAPAL } \\
\hline \multicolumn{8}{|c|}{ REPORT ON INCLINING TEST } \\
\hline \multirow{14}{*}{$\begin{array}{l}\frac{\bar{x}}{c} \\
\frac{1}{\sigma} \\
\tilde{n} \\
\tilde{\pi} \\
\frac{\pi}{n} \\
\tilde{D} \\
\frac{0}{\pi} \\
\underline{0}\end{array}$} & \multirow{14}{*}{$\begin{array}{l}\text { 売 } \\
0 \\
0 \\
0 \\
0 \\
\frac{0}{0} \\
0\end{array}$} & & NAMA TANKI & KAPASITAS PENUH & JENIS CAIRAN & MASSA JENIS & ISI TANKI \\
\hline & & NO & TANK NAME & FULL CAPACITY & TYPE OF LIQUID & SPECIFIC GRAVITY & PRESENT CAPACITY \\
\hline & & & & (TON) & & (TON/M3) & (TON) \\
\hline & & 1 & F.O.TANK (P) & 7,355 & Fuel Oil & 0,9443 & 0 \\
\hline & & 2 & F.O.TANK (S) & 7,355 & Fuel Oil & 0,9443 & 0 \\
\hline & & 3 & DAILY TANK & & Fuel Oil & 0,9443 & 0,632 \\
\hline & & 4 & SERIVICE TANK & 1,968 & Fuel Oil & 0,9443 & 0 \\
\hline & & 5 & SEWAGE TANK & 1,688 & Slops Oil & 0,9130 & 0 \\
\hline & & 6 & BILGE TANK & & Slops Oil & 0,9130 & 0 \\
\hline & & 7 & SLUDGE TANK & 0,957 & Slops Oil & 0,9130 & 0 \\
\hline & & 8 & FRESH WATER (P) & 2,995 & Fresh Water & 0,9200 & 0 \\
\hline & & 9 & FRESH WATER (S) & 2,995 & Fresh Water & 0,9200 & 0 \\
\hline & & 10 & Water Ballast (P) & 4,340 & Sea Water & 1,0250 & 0 \\
\hline & & 11 & Water Ballast (S) & 4,340 & Sea Water & 1,0250 & 0 \\
\hline
\end{tabular}

Berdasarkan rules yang telah ada, untuk semua barang yang dinaikkan, diturunkan atau dipindahkan harus dicatat secara cermat agar hasil yang didapat tidak mengalami kekeliruan, berikut hasil laporan pengujian kemiringan berdasarkan bagian yang dikurangi dan ditambah maka didapatkan hasil sebagai berikut

TABEL 8

BEBAN YANG DIKURANGI

\begin{tabular}{|c|c|c|c|c|c|c|c|c|}
\hline \multirow{8}{*}{ 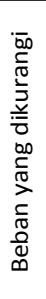 } & \multirow{8}{*}{ 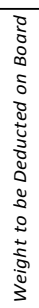 } & \multirow{2}{*}{ No } & \multirow{2}{*}{ ITEM } & WEIGHT & $L C G$ & MOMENT & VCG & MOMENT \\
\hline & & & & (TON) & (M) & (TON.M) & (M) & (TON.M) \\
\hline & & 1 & TEST PERSONEL (7 PERSONS) & 0,525 & 2,400 & 1,260 & 4,100 & 2,153 \\
\hline & & 2 & TEST WEIGHT 1 & 1,105 & 7,200 & 7,956 & 3,550 & 3,923 \\
\hline & & 3 & TEST WEIGHT 2 & 1,105 & 6,000 & 6,630 & 3,550 & 3,923 \\
\hline & & 4 & TEST WEIGHT 3 & 1,105 & 4,800 & 5,304 & 4,080 & 4,508 \\
\hline & & 5 & TEST WEIGHT 4 & 1,105 & 3,600 & 3,978 & 4,080 & 4,508 \\
\hline & & 6 & DAILY TANK & 0,632 & & & & \\
\hline & & TAL & WEIGHT TO BE DEDUCTED & 5,577 & 24,000 & 25,128 & 19,360 & 19,015 \\
\hline
\end{tabular}

\section{2) Stability Calculation}

Stability Calculation dibagi menjadi 3 kondisi Sehingga diketahui stabilitas di tiap-tiap kondisi dengan berat kapal kosong 40,23 Ton. Masing-masing kondisi beban pada saat pengujian stabilitas dapat dilihat pada tabel 9, 10 dan 11.

Dari Kurva GZ dibawah ini didapatkan bahwa :

1. Besar lengan penegak (GZ) pada kondisi pertama nilai GZ naik sampai sudut $50^{\circ}$ dan kemudian turun setelah sudut $50^{\circ}$. Dengan nilai GZ maksimum 0,840 pada saat sudut oleng $50^{\circ}$.

2. Besar lengan penegak (GZ) pada kondisi kedua nilai GZ naik sampai sudut $50^{\circ}$ dan kemudian turun setelah sudut $50^{\circ}$. Dengan nilai GZ maksimum 0,840 pada saat sudut oleng $50^{\circ}$.

3. Besar lengan penegak (GZ) pada kondisi ketiga nilai GZ naik sampai sudut $40^{\circ}$ dan kemudian turun setelah sudut $40^{\circ}$. Dengan nilai GZ maksimum 0,798 pada saat sudut oleng $40^{\circ}$. 
TABEL 12

TABEL 9

PENGUJIAN STABILITAS DENGAN BEBAN PENUH TERMASUK TAHANAN KAPAL

\begin{tabular}{|l|c|c|c|c|c|}
\hline \multicolumn{1}{|c|}{ Item } & Qty & Weight $(\mathbf{t})$ & Volume $\left(\mathbf{m}^{\wedge} \mathbf{3}\right)$ & LCG $(\mathbf{m})$ & VCG $(\mathbf{m})$ \\
\hline Lightship & 1 & 40,23 & & 10,63 & 1,89 \\
\hline F.0.T(P) & $98 \%$ & 7,20 & 7,63 & 11,08 & 0,62 \\
\hline F.0.T(S) & $98 \%$ & 7,20 & 7,63 & 11,08 & 0,62 \\
\hline F.W.T (P) & $98 \%$ & 2,93 & 2,93 & 2,10 & 1,21 \\
\hline F.W.T(S) & $98 \%$ & 2,93 & 2,93 & 2,10 & 1,21 \\
\hline Service Tank & $98 \%$ & 1,93 & 2,04 & 3,33 & 1,97 \\
\hline W.B.T (P) & $0 \%$ & 0,00 & 0,00 & 17,41 & \\
\hline W.B.T (S) & $0 \%$ & 0,00 & 0,00 & 17,41 & \\
\hline Prisoner & 6 & 0,45 & & 23,40 & 1,40 \\
\hline \multicolumn{7}{|c|}{ Total } & 62,87 & 23,16 & 98,54 & 8,92 \\
\hline
\end{tabular}

TABEL 10

PENGUJIAN STABILITAS DENGAN BEBAN PENUH TANPA TAHANAN KAPAL

\begin{tabular}{|l|c|c|c|c|c|}
\hline \multicolumn{1}{|c|}{ Item } & Qty & Weight $(\mathbf{t})$ & Volume $\left(\mathbf{m}^{\wedge} \mathbf{3}\right)$ & LCG $(\mathbf{m})$ & VCG $(\mathbf{m})$ \\
\hline Lightship & 1 & 40,23 & & 10,63 & 1,89 \\
\hline F.O.T (P) & $98 \%$ & 7,20 & 7,63 & 11,08 & 0,62 \\
\hline F.O.T (S) & $98 \%$ & 7,20 & 7,63 & 11,08 & 0,62 \\
\hline F.W.T (P) & $98 \%$ & 2,93 & 2,93 & 2,10 & 1,21 \\
\hline F.W.T (S) & $98 \%$ & 2,93 & 2,93 & 2,10 & 1,21 \\
\hline Service Tank & $98 \%$ & 1,93 & 2,04 & 3,33 & 1,97 \\
\hline W.B.T (P) & $0 \%$ & 0,00 & 0,00 & 17,41 & \\
\hline W.B.T (S) & $0 \%$ & 0,00 & 0,00 & 17,41 & \\
\hline Prisoner & 0 & 0,00 & & 23,40 & 1,40 \\
\hline \multicolumn{2}{|c|}{ Total } & $\mathbf{6 2 , 4 2}$ & $\mathbf{2 3 , 1 6}$ & $\mathbf{9 8 , 5 4}$ & $\mathbf{8 , 9 2}$ \\
\hline
\end{tabular}

TABEL 11

PENGUJIAN STABILITAS DENGAN KONDISI KAPAL KOSONG

\begin{tabular}{|l|c|c|c|c|c|}
\hline \multicolumn{1}{|c|}{ Item } & Qty & Weight $(\mathrm{t})$ & Volume $\left(\mathrm{m}^{\wedge} \mathbf{3}\right)$ & LCG $(\mathrm{m})$ & VCG (m) \\
\hline Lightship & 1 & 40,23 & & 10,63 & 1,89 \\
\hline F.O.T(P) & $0 \%$ & 0,00 & 0,00 & 13,18 & 0,00 \\
\hline F.O.T(S) & $0 \%$ & 0,00 & 0,00 & 13,18 & 0,00 \\
\hline F.W.T (P) & $0 \%$ & 0,00 & 0,00 & 2,99 & 0,43 \\
\hline F.W.T(S) & $0 \%$ & 0,00 & 0,00 & 2,99 & 0,43 \\
\hline Service Tank & $0 \%$ & 0,00 & 0,00 & 3,33 & 1,03 \\
\hline W.B.T(P) & $0 \%$ & 0,00 & 0,00 & 19,43 & 0,00 \\
\hline W.B.T(S) & $0 \%$ & 0,00 & 0,00 & 19,43 & 0,00 \\
\hline Prisoner & 0 & 0,00 & & 23,40 & 1,40 \\
\hline \multicolumn{7}{|c|}{ Total } & 40,23 & 0,00 & 108,56 & $\mathbf{5 , 1 8}$ \\
\hline
\end{tabular}

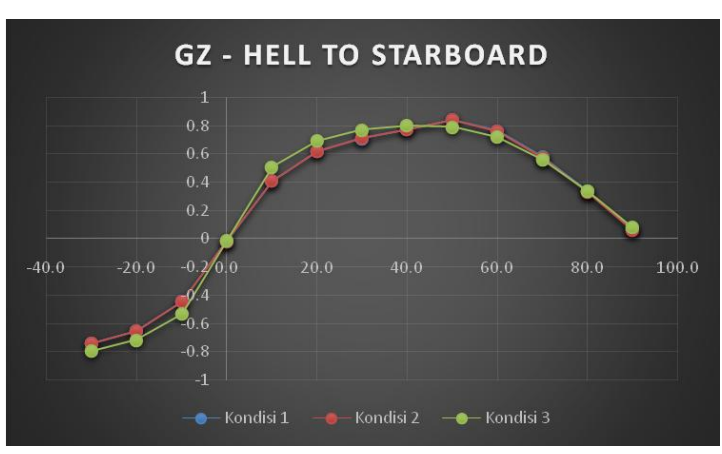

Figure 6: Kurva GZ
HASIL TINGGI METACENTER (GM0)

\begin{tabular}{|c|c|c|c|}
\hline \multirow{2}{*}{ Nilai } & \multicolumn{3}{|c|}{ Kondisi } \\
\hline & Kondisi 1 & Kondisi 2 & Kondisi 3 \\
\hline Lwl & $25,050 \mathrm{~m}$ & $24,850 \mathrm{~m}$ & $25,020 \mathrm{~m}$ \\
\hline $\mathrm{Cb}$ & 0,497 & 0,497 & 0,385 \\
\hline $\mathrm{T}$ & $0,920 \mathrm{~m}$ & $0,910 \mathrm{~m}$ & $0,734 \mathrm{~m}$ \\
\hline B (yang terbenam diair) & $5,050 \mathrm{~m}$ & $4,950 \mathrm{~m}$ & $5010 \mathrm{~m}$ \\
\hline ро & 1,025 ton $/ \mathrm{m} 3$ & 1,025 ton/m4 & 1,025 ton $/ \mathrm{m5}$ \\
\hline $\mathrm{w}$ & 4,420 ton & 4,420 ton & 4,420 ton \\
\hline 1 & $4,200 \mathrm{~m}$ & $4,200 \mathrm{~m}$ & $4,200 \mathrm{~m}$ \\
\hline W & 59,288 ton & 57,023 ton & 36308 ton \\
\hline $\operatorname{Tan} \theta$ & 1.556 & 1.556 & 1.556 \\
\hline Gm0 & $0,201 \mathrm{~m}$ & $0,209 \mathrm{~m}$ & $0,328 \mathrm{~m}$ \\
\hline
\end{tabular}

Berdasarkan Rumus perhitungan tinggi metacenter persamaan (3) maka didapatkan hasil tinggi metacenter dapat dilihat pada tabel 12. Dari tabel tersebut maka didapatkan hasil untuk kondisi 1 nilai $\mathrm{GM}_{0} 0,201 \mathrm{~m}$, kondisi 2 nilai $\mathrm{GM}_{0} 0,209 \mathrm{~m}$, kondisi $3 \mathrm{GM}_{0} 0,328 \mathrm{~m}$.

\section{Kesimpulan}

Dari hasil analisa dan pembahasan maka didapatkan beberapa kesimpulan sebagai berikut :

1. Berdasarkan rules BKI Vol C petunjuk pengujian kemiringan kapal di 2.5.3 menjelaskan bahwa beban uji harus cukup untuk memiringkan kapal paling sedikit $1^{\circ}$ dan palig besar $4^{\circ}$ terhitung dari posisi awal. Untuk pengujan kemiringan kapal patroli $28 \mathrm{~m}$ yang dilakukan dengan 3 kondisi dan diukur kemiringannya sudah memenuhi syarat tersebut baik untuk bagian depan (fore) maupun bagian belakang (aft).lihat tabel 3.3. Laporan Pengujian Kemiringan Kapal (kondisi kapal penuh termasuk tahanan), 3.4. Laporan Pengujian Kemiringan Kapal (kondisi kapal penuh tanpa tahanan), dan tabel 3.5. Laporan Pengujian Kemiringan Kapal (kondisi kapal kosong).

2. Berdasarkan IMO Regulation Section A. 749(18), Chapter 3.1.2.2 untuk nilai GZ minimal 0,20 m pada kemiringan lebih dari $30^{\circ}$ [10], Oleh karena itu pada kondisi 1, 2, dan 3 telah memenuhi syarat yang telah ditentukan IMO.

3. Biro Klasifikasi Indonesia telah mengatur bahwa kapal memiliki stabilitas yang memadai, stabilitas positif dan tegangan yang timbul masih dapat diterima dengan tinggi metacenter $\left(\mathrm{GM}_{0}\right)$ paling sedikit $0,20 \mathrm{~m}$. Dan berdasarkan IMO Regulation Section A.749 (18), Chapter 3.1.2.4 tinggi metacenter minimal 0,15 m [10]. Berikut tabel nilai tinggi metacenter $\left(\mathrm{GM}_{0}\right)$. 
TABEL 13

Perhitungan TingGi Metacenter (GM0)

\begin{tabular}{|c|c|c|c|c|}
\hline \multirow{2}{*}{ KONDISI } & \multirow{2}{*}{$\begin{array}{l}\text { DISPLACEMENT } \\
\text { (ton) }\end{array}$} & \multicolumn{2}{|c|}{ GM0 } & \multirow{2}{*}{ Keterangan } \\
\hline & & Depan (Fore) & Belakang (Aft) & \\
\hline Kondisi 1 & 59,2881 & 0,2012 & 0,2012 & Pass \\
\hline Kondisi 2 & 57,0234 & 0,2092 & 0,2092 & Pass \\
\hline Kondisi 3 & 36,3083 & 0,3285 & 0,3285 & Pass \\
\hline
\end{tabular}

Dari hasil perhitungan tersebut menunjukan bahwa semakin besar berat displacement maka semakin kecil tinggi metacenter. Oleh karena itu kapal patroli $28 \mathrm{~m}$ ini sudah memenuhi standar yang ada dikarenakan tinggi metacenter sudah memenuhi standar yang ditentukan BKI dan IMO Regulation.

Beban uji merupakan satu komponen yang diperlukan didalam pengujian kemiringan kapal, untuk berat beban uji telah ditentukan oleh BKI. Tinggi metacenter sangat dipengaruhi oleh berat beban uji dan sudut senget kapal, dikarenakan semakin kecil berat displacement maka semakin besar nilai $\mathrm{GM}_{0}$. Dan untuk mendapatkan nilai GZ dibutuhkan tinggi metacenter $\mathrm{GM}_{0}$

\section{References}

[1] Capt, Albertus, Hardjanto M, Mar. 2010. Pengaruh Kelebihan Dan Pergeseran Muatan Di Atas Kapal Terhadap Stabilitas Kapal. Universitas Hang Tuah

[2] KNKT. 2016. Data Investigasi Kecelakaan Pelayaran Tahun 2010-2016. Jakarta : Komite Nasional Keselamatan Transportasi.

[3] Siti, Nafisah, Matafi., Heffry V, Dien., Fransisco, P.T, Pangalila. 2015. Simulasi Pengaruh Trim Terhadap Stabilitas Kapal Pukat Cincin. Manado : Universitas Sam Ratulangi

[4] Fransisco, P.T, Pangalila. 2011. Stabilitas Statis Kapal Pole And Line KM Aldeis Di Pelabuhan Perikanan Aertembaga Bitung Sulawesi Utara. Manado : Universitas Sam Ratulangi

[5] Hind,J.A. 1967. Trim And Stability Of Fishing Vessel. London

[6] Andre, Yohanes, Hamonangan, Hutabarat. 2009. Simulasi Uji Stabilitas Kapal Dengan Metode Teori Kapal Model. Depok : Universitas Indonesia

[7] Kiryanto. 2010. Analisa Teknis Stabilitas Dan Olah Gerak Kapal Patrol Speed Boat "Grass Carp” Di Perairan Rawa Pening Jawa Tengah. Semarang : Universitas Diponegoro
[8] Rizki, Mulya, Sari. 2010. Stabilitas Statis Kapal Payang Madura. Bogor : Institut Pertanian Bogor

[9] BKI. 2003. Vol C 2003 Petunjuk Pengujian Kemiringan Dan Periode Oleng Kapal. Jakarta : Biro Klasifikasi Indonesia

[10] Jan. 2006. Stability Information Manual. Chengxi Shipyard. 